\title{
Analysis of Long Noncoding RNA and mRNA Profiling in Peripheral Blood Mononuclear Cells of Human Immunized With Rabies Virus Vaccine by RNA Sequencing
}

Pingsen Zhao ( $\sim$ zhaopingsen01@163.com)

Department of Laboratory Medicine, Yuebei People's Hospital, Shantou University Medical College, Shaoguan, China 2Shaoguan Municipal Quality Control Center for Laboratory Medicine, Shaoguan, China https://orcid.org/0000-0001-5178-3664

Kaijian Hou

Shantou University

Peibin Zeng

Sichuan University

Songtao Yang

Academy of Military Medical Sciences

Xianzhu Xia

Academy of Military Medical Sciences

Research article

Keywords: rabies virus (RABV), rabies virus vaccine, immunization, high-throughput sequencing, long noncoding RNA, bioinformatics analysis

Posted Date: August 20th, 2020

DOI: https://doi.org/10.21203/rs.3.rs-50067/v1

License: (c) (1) This work is licensed under a Creative Commons Attribution 4.0 International License. Read Full License 


\section{Abstract \\ Background}

Rabies is still a lethal disease caused by rabies virus (RABV), and it remains a global health threaten. The epigenetic landscape of host in response to immunization with rabies virus vaccine is not yet elucidated. Evidences reveal that long noncoding RNA (IncRNA) play an important role for control of viral infection, but the expression profile of IncRNA in human immunized with rabies virus vaccine remains unclear.

\section{Methods}

IncRNA and mRNA profiles were investigated in four volunteers vaccinated with RABV vaccine by RNA sequencing.

\section{Results}

33 InRNAs and 427 mRNAs were differentially expressed in RABV vaccine immunized volunteers. The gene oncology (GO) and Kyoto Encyclopedia of Genes and Genomes (KEGG) were used to analysis the functional annotation, and the result suggested the IncRNAs involved in signaling pathways related to host immune induced by the RABV vaccine.

\section{Conclusions}

To the best of our knowledge, it is the first time to report the transcriptomic landscape of IncRNAs in human immunized with RABV vaccine. Our study mimics the host response of human to RABV infection and suggests that IncRNAs might be of a potential therapeutic target in anti-rabies virus strategies.

\section{Background}

Rabies is not only one of the oldest diseases in human history, also is one of the deadliest zoonosis disease[1]. Since the clinical symptoms had developed, the mortality rate is almost $100 \%$ [2]. No matter in developing or developed country, the rabies viral (RABV) post a serious threat to the publish health [3]. Annually the more than 70000 human deaths result from the rabies viral infection and Asia is the disaster stricken area among the worldwide[4].

RABV belongs to the family Rhabdoviridae, genus Lyssavirus, and it is one of the most important zoonosis affecting the central nervous of mammals [5]. RABV has an approximately $12 \mathrm{~kb}$ negative-sense RNA genome which encodes five structural proteins: the nucleoprotein ( $\mathrm{N}$ ), phosphoprotein (P), matrix protein $(M)$, glycoprotein $(G)$ and RNA-dependent RNA polymerase $(L)$ [6]. Following infection, the RABV virus replicates locally in muscle tissue and then travelled within axons in the peripheral nervous system (PNS) via retrograde axonal [7]. Once the clinical symptoms of rabies had developed, it elicit neuronal dysfunction and lead to death[8].

During the infection, the host innate immune system sensed the microorganisms invasion and induced the cytokines secretion by pattern-recognition receptors (PRRs) $[9,10]$. The cytokines contains type I interferons (IFNa/ $\beta$ ), inflammatory cytokines, and chemokines and so on. Here in the RABV infection, the IFN-mediated immune response is the most important way in antiviral state [11, 12]. The type I IFN-IFNR signal way activates Janus-activated kinase/signal transducer(JAK/STAT)[13], result in the transcription of hundreds of IFN-stimulated genes(ISGs)[14, 15]. ISGs exert diverse antiviral effects as the effector of type I IFN response [16, 17], and inhibit the IFN mediated respond against RABV infection aggravate viral infection in vitro and in vivo [18, 19]. Although some studies demonstrated the importance of IFN mediated response against RABV infection, the mechanism by which RABV causes fatal disease remains unclear.

RABV infection can induce the host immune system responds, and the long noncoding RNAs (IncRNA) affect many cellular processes as an effector in the immune system during the infection[20, 21], such as differentiation[22], apoptosis[23], development[24], and immune responses[25]. Studies had reported that viral infections such as influenza (IAV)[26], HIV[27], hepatitis B[28] could induce specific IncRNA promote or suppress antiviral responses[29]. Most ISGs and some cellular factor play a role of antiviral or proviral function and it had been shown that IFN pathway regulates the expression of some IncRNAs. Viralinduced IncRNAs should decrease the antiviral response, while cellular IncRNAs induced by infection could either induce the pathway or decrease IFN synthesis and signaling to control the duration and the strength of the antiviral response[30-32]. Hironori et al., report that the IncRNA\#32 silence could reduce ISG expression, exerted anti-virus infection which suggest IncRNA\#32 positively regulates the host antiviral response[33].However, little is known about IncRNA expression profile after RABV infection and their regulating role in innate immune against RABV. In our previous work, we first had analysis the expression profiles of IncRNAs and mRNAs in brains of mice infected by rabies virus and found some differentially expressed IncRNA and mRNA[34]. What's more, we are studying the mechanism of some selected IncRNA anti-viral function.

To investigate how the IncRNA respond during the RABV infection, we use a commercial RABV vaccine to develop a model to simulate the viral induced immune respond. We analyzed the IncRNA expression profile in peripheral blood mononuclear cells (PBMCs) of volunteers after RABV vaccine immunized by RNA-SEq. The data reveal that RABV vaccine induced significant expression of IncRNA and mRNA. Gene ontology (GO) and KEGG analysis suggested IncRNA involve in the host immune response induce by the RABV vaccine. To our knowledge, this is the first study to profile the IncRNA expression induced by the RABV vaccine and the finding base on the RABV vaccine would be useful for the understanding the infection between RABV and host immunity.

\section{Methods}




\section{Experimental design}

All the volunteers enrolled for this study had all signed the Informed Consent, and the study was performed in accordance with the Declaration of Helsinki and was approved by the Research Ethics Committee of Yuebei People's Hospital, Shantou University Medical College, Shaoguan, China.

All the four healthy volunteers with no rabies virus vaccine history, were recruited to receive three doses of Rabies Vaccine (Vero Cell) for Human Use (China Food and Drug Admistration approval number: S20120016) (Changsheng Bio-technology Co., Ltd). The vaccine is a fixed rabies vaccine virus aG strain, which was inoculated into Vero cells and culture in a bioreactor microcarries. After culture, the virus solution was harvested, inactivated, purified and lyophilized with appropriate stabilizers. The titer of the rabies vaccine is not lower than $2.5 \mathrm{IU}$. The vaccinate procedure was followed the pre-exposure procedure according to the manufacturer's instructions. It contained 3 injections: 1 dose was injected on 0 days, 7 days, 21 days (Fig. 1 ). And 10 ml peripheral blood samples were obtained from the volunteers at day 0 before vaccinated and the 28-days, the PBMCs had been separated immediately using Ficoll-Paque (GE Healthcare) gradient centrifugation for further sequence.

\section{Total Rna Extraction}

Total RNA was extracted from PBMC according to the manufacturer's protocol (TRIzol ${ }^{\mathrm{TM}}$ Reagent, Invitrogen). The quantity and purity of total RNA were evaluated by Nanodrop 2000. The ratio of A260/A280 should be from 1.8 to 2.0. RNA integrity was analyzed by the Bioanalyzer 2100 system (Agilent Technologies, CA, USA).

\section{High Throughput Sequencing}

Ribo-Zero rRNA removal kit (Epicentre, USA) was used to remove ribosomal RNA. The rRNA-depleted RNA with NEBNext® Ultra ${ }^{\mathrm{TM}}$ Directional RNA Library Prep Kit (NEB, USA) for Illumina was used for preparation of the RNA libraries. Library sequencing was performed on an Illumina HiSeq 2000 platform with 150 bp read length in ShenZhen Realomics Inc.

\section{Bioinformatic Analysis}

With the Illumina HiSeq 2000 platform, The sequence raw data was filtered by the low quality reads, like the adaptors, low-quality reads and poly-N reads, to obtain clean data using the SOAPnuke. The filtered contain removal of adapter reads; removal of low-quality reads (the base number of $\mathrm{sQ}<=5$ accounts for more than $50 \%$ of the whole read); removal of the base information that undetermined ratio of reads is more than $10 \%$. The QC checks is performed on the clean data to determine the suitable data for subsequent analysis, such as the Q20, Q30, and GC information. The filtered reads were mapped to the human reference genome by Tophat2 (Version 2.1.1).Then the mapped reads were assembled by reference annotation with transcripts method Cufflink (Version 2.2.1) [35]. LncRNA transcripts exceed $200 \mathrm{nt}$ and do not encode proteins. According to the characteristics of the IncRNA structure and the functional characteristics, the candidate novel IncRNA is obtained should accord with the followed requirement: (1) exon number $\geq 2$, (2) length $>200$ nt, (3) FPKM $\geq 0.5$, (4) without coding capacity, (5) don't overlap with mRNA or annotated IncRNA. Coding ability was predicted using coding-non-coding-index (CNCl)[36], coding potential calculator (CPC)[37] and coding-potential assessment tool (CPAT)[38]. Cuffdiff (version 2.2.1) was used to analysis the expression, the function analysis was performed with the GO (www.geneontology.org) and KEGG (http://www.genome.ad.jp/kegg/). GO terms analyses were performed to identify biological processes enriched in neighboring genes of predicted co-localized IncRNA. KEGG was used to analyze the enriched pathways of co-expressed genes for the predicted co-localized IncRNA. Q values $<0.05$ were considered as significantly enriched pathways.

\section{Quantitative Real-time Pcr Validation}

The surplus of the RNA sample for the RNA-Seq was used for quantitative real-time polymerase chain reaction (RT-qPCR) validation. RT-qPCR was used the Luna ${ }^{8}$ Universal One-Step RT-qPCR Kit (NEB, USA) in LightCycler480 II (Roche, USA) according to the manufacturer's instructions. The reaction conditions were set as follows: reverse transcription at $55^{\circ} \mathrm{C}$ for $10 \mathrm{~min}$, initial denaturation at $95^{\circ} \mathrm{C}$ for $1 \mathrm{~min}$, followed by 40 cycles of $95^{\circ} \mathrm{C}$ for $10 \mathrm{~s}, 60^{\circ} \mathrm{C}$ for $30 \mathrm{~s}$, and $72^{\circ} \mathrm{C}$ for $30 \mathrm{~s}$. The specificity of the amplified products was evaluated by using dissociation curves. The relative expression levels of IncRNAs were calculated using the $2^{-\triangle \triangle C t}$ method and were normalized by GADPH. The tests were triplicated.

\section{Statistical analysis}

Data were analyzed using Student's t-test or one-way ANOVA followed by Dunnett's multiple comparison test (compare post-immunized groups to the preimmunized group). All data are demonstrated as the means \pm S.D. $\left({ }^{\star} P<0.05,{ }^{*} P<0.01,{ }^{\star * \star} P<0.001\right)$. For correlation studies, a two-tailed non-parametric Spearman analysis was used. $P \leq 0.05$ were considered as significant.

\section{Results}

Identification of differentially expressed IncRNAs in PBMCs of human immunized with rabies virus vaccine by RNA-seq

To investigate the IncRNA expression profile in the volunteers induced by the RABV vaccine, high throughput RNA sequencing was performed on the PBMC of volunteers immunized with RABV vaccine. We sequenced 8 rRNA-deprived total RNA samples obtained from 4 volunteers pre- and post-immunized with RABV 
vaccine. Average 86 million raw reads were produced from Illumina HiSeq platform. By the bioinformatic analysis, the raw data was filter out for further analysis.

Because of the specific structure and non-coding characteristics of IncRNA, 5-step scanned was used to analysis the transcripts to identify the annotated IncRNA and novel IncRNA. Finally 558 novel IncRNA were assembled by Cuffilink (Fig. 2A). CNCl, CPC and CPAT were used to evaluate the coding capacity of transcripts (Fig. 2B). Moreover, with the relative location to the coding genes, the IncRNA identified were divided into five classifications include intergenic IncRNA (74.55\%), intronic IncRNA (10.22\%), antisense IncRNA (6.63\%), enhancer IncRNA (3.41\%) and bidirectional IncRNA (5.20\%) (Fig. 2C).

The IncRNA expression profiles in eight sample of four volunteers pre- and post-immunized with RABV vaccine were analyzed with hierarchical clustering. The result showed that IncRNA expression profiles were significantly modified after RABV vaccine immunized (Fig. 3A). There was 33 IncRNA were expressed significant different, including 1 upregulated and 32 downregulated (Fig. 3B). The upregulated IncRNA was ENSG00000254162 with a fold change (FC) of 4.38 compared to the post-immunized and the downregulated IncRNA had a FC range 1.75 to 7.07 (Table 1). All the differentially expressed IncRNA were listed in Table 1. The number distribution of IncRNA in all chromosomes was display in Fig. 3C and it showed that chromosome 5 had the highest number of IncRNA, while chromosome 3, 4, 6 and so on had only one IncRNA. However, several chromosomes didn't have any significant different IncRNA like chromosome 2, 10, et.al (Fig. 3C).

\section{Identification of differentially expressed mRNAs in PBMCs of human immunized with rabies virus vaccine by RNA-seq}

We examined the different expression of mRNA after the RABV vaccine immunized, and significant difference expression of mRNA induced by RABV vaccine was showed by hierarchical cluster analysis (Fig. 4). In our study, 427 mRNA were differentially expressed after RABV vaccine immunized, including 321 upregulated and 106 downregulated (Fig. 4B). In the different expression genes, the most upregulated one was HSPA1B (FC = 14.84) and the top 3 downregulated were CLC ( FC = 27.00), DEFA3 ( FC = 15.54) and CAMP $(F C=11.96)$. The top 20 differentially expressed genes were listed in Table 2. Unlike the IncRNA, the mRNA distributed to all the chromosome but were not equally scattered among chromosomes. The chromosome 1 had the most differentially expressed mRNAs and chromosome 14 and 18 had the least numbers (Fig. 4C).

Table 1. Differentially expressed IncRNAs in peripheral blood mononuclear cells of human immunized by RABV vaccine by RNA sequencing. 


\begin{tabular}{|c|c|c|c|c|c|c|c|c|}
\hline Gene_id & Isoform_status & $\begin{array}{l}\text { Post- } \\
\text { immunized }\end{array}$ & $\begin{array}{l}\text { Pre- } \\
\text { immunized }\end{array}$ & log2FoldChange & p_value & q_value & Dysregulated & FC \\
\hline ENSG00000245164 & IncRNA_annotated & 5.34448 & 9.3865 & -0.81254 & 0.0002 & 0.020468 & Down & 1.756297 \\
\hline XLOC_042681 & IncRNA_Novel & 2.31781 & 4.21036 & -0.86119 & $\begin{array}{l}5.00 \mathrm{E}- \\
05\end{array}$ & 0.006587 & Down & 1.81653 \\
\hline ENSG00000215458 & IncRNA_annotated & 6.22621 & 11.3207 & -0.86254 & $\begin{array}{l}5.00 \mathrm{E}- \\
05\end{array}$ & 0.006587 & Down & 1.818237 \\
\hline ENSG00000261490 & IncRNA_annotated & 3.0043 & 5.63895 & -0.9084 & 0.00045 & 0.038471 & Down & 1.876961 \\
\hline ENSG00000269821 & IncRNA_annotated & 1.20099 & 2.28741 & -0.92949 & $\begin{array}{l}5.00 \mathrm{E}- \\
05\end{array}$ & 0.006587 & Down & 1.904599 \\
\hline XLOC_051604 & IncRNA_Novel & 2.42931 & 4.71665 & -0.95722 & $\begin{array}{l}5.00 \mathrm{E}- \\
05\end{array}$ & 0.006587 & Down & 1.94156 \\
\hline ENSG00000281103 & IncRNA_annotated & 4.09089 & 8.10076 & -0.98564 & 0.0001 & 0.011848 & Down & 1.980194 \\
\hline ENSG00000266962 & IncRNA_annotated & 6.01747 & 12.0116 & -0.99721 & 0.0005 & 0.041152 & Down & 1.996129 \\
\hline XLOC_018471 & IncRNA_Novel & 0.977134 & 1.95301 & -0.99907 & 0.00015 & 0.016397 & Down & 1.998714 \\
\hline XLOC_024827 & IncRNA_Novel & 0.902814 & 1.94629 & -1.10822 & $\begin{array}{l}5.00 \mathrm{E}- \\
05\end{array}$ & 0.006587 & Down & 2.155795 \\
\hline ENSG00000235314 & IncRNA_annotated & 3.66534 & 8.05664 & -1.13623 & 0.00055 & 0.044236 & Down & 2.198059 \\
\hline XLOC_056429 & IncRNA_Novel & 1.21387 & 2.79502 & -1.20324 & 0.0005 & 0.041152 & Down & 2.302562 \\
\hline XLOC_050760 & IncRNA_Novel & 2.77627 & 6.39987 & -1.2049 & $\begin{array}{l}5.00 \mathrm{E}- \\
05\end{array}$ & 0.006587 & Down & 2.305213 \\
\hline XLOC_056637 & IncRNA_Novel & 0.509636 & 1.20423 & -1.24057 & $\begin{array}{l}5.00 \mathrm{E}- \\
05\end{array}$ & 0.006587 & Down & 2.362919 \\
\hline XLOC_049174 & IncRNA_Novel & 0.774507 & 1.85106 & -1.257 & $\begin{array}{l}5.00 \mathrm{E}- \\
05\end{array}$ & 0.006587 & Down & 2.389982 \\
\hline XLOC_041020 & IncRNA_Novel & 1.62414 & 3.8977 & -1.26295 & $\begin{array}{l}5.00 \mathrm{E}- \\
05\end{array}$ & 0.006587 & Down & 2.39986 \\
\hline XLOC_059380 & IncRNA_Novel & 0.770727 & 1.85765 & -1.26919 & 0.00045 & 0.038471 & Down & 2.410262 \\
\hline XLOC_062407 & IncRNA_Novel & 0.472431 & 1.20236 & -1.3477 & 0.0002 & 0.020468 & Down & 2.545061 \\
\hline XLOC_023926 & IncRNA_Novel & 0.560945 & 1.42784 & -1.3479 & 0.00065 & 0.049892 & Down & 2.545413 \\
\hline XLOC_016347 & IncRNA_Novel & 0.82775 & 2.12904 & -1.36294 & $\begin{array}{l}5.00 \mathrm{E}- \\
05\end{array}$ & 0.006587 & Down & 2.572088 \\
\hline XLOC_051558 & IncRNA_Novel & 0.922673 & 2.38183 & -1.36818 & $\begin{array}{l}5.00 \mathrm{E}- \\
05\end{array}$ & 0.006587 & Down & 2.581447 \\
\hline ENSG00000230733 & IncRNA_annotated & 0.824332 & 2.15159 & -1.38411 & 0.00025 & 0.024656 & Down & 2.610109 \\
\hline XLOC_051602 & IncRNA_Novel & 0.684579 & 1.84391 & -1.42948 & $\begin{array}{l}5.00 \mathrm{E}- \\
05\end{array}$ & 0.006587 & Down & 2.693496 \\
\hline XLOC_051172 & IncRNA_Novel & 0.654121 & 1.98247 & -1.59967 & $\begin{array}{l}5.00 \mathrm{E}- \\
05\end{array}$ & 0.006587 & Down & 3.03074 \\
\hline XLOC_066116 & IncRNA_Novel & 0.83044 & 2.59132 & -1.64174 & $\begin{array}{l}5.00 \mathrm{E}- \\
05\end{array}$ & 0.006587 & Down & 3.12042 \\
\hline ENSG00000214894 & IncRNA_annotated & 1.09692 & 3.73051 & -1.76592 & $\begin{array}{l}5.00 \mathrm{E}- \\
05\end{array}$ & 0.006587 & Down & 3.400908 \\
\hline XLOC_003374 & IncRNA_Novel & 1.10497 & 3.8463 & -1.79947 & $\begin{array}{l}5.00 \mathrm{E}- \\
05\end{array}$ & 0.006587 & Down & 3.480923 \\
\hline XLOC_005414 & IncRNA_Novel & 0.533678 & 1.92461 & -1.85053 & 0.0002 & 0.020468 & Down & 3.606326 \\
\hline XLOC_062716 & IncRNA_Novel & 0.399621 & 1.84311 & -2.20543 & $\begin{array}{l}5.00 \mathrm{E}- \\
05\end{array}$ & 0.006587 & Down & 4.61212 \\
\hline XLOC_005417 & IncRNA_Novel & 0.363757 & 1.69681 & -2.22177 & $\begin{array}{l}5.00 \mathrm{E}- \\
05\end{array}$ & 0.006587 & Down & 4.664654 \\
\hline ENSG00000197182 & IncRNA_annotated & 0.408312 & 1.96928 & -2.26992 & 0.0004 & 0.035132 & Down & 4.822964 \\
\hline XLOC_000161 & IncRNA_Novel & 0.492994 & 3.48758 & -2.82259 & $\begin{array}{l}5.00 \mathrm{E}- \\
05\end{array}$ & 0.006587 & Down & 7.074313 \\
\hline ENSG00000254162 & IncRNA_annotated & 3.30507 & 0.75435 & 2.13138 & $5.00 \mathrm{E}-$ & 0.006587 & Up & 4.381364 \\
\hline
\end{tabular}


Table 2. Differentially expressed mRNAs in peripheral blood mononuclear cells of human immunized by RABV vaccine by RNA sequencing

\begin{tabular}{|c|c|c|c|c|c|c|c|c|c|}
\hline Gene_id & Gene & Isoform_status & $\begin{array}{l}\text { Post- } \\
\text { immunized }\end{array}$ & $\begin{array}{l}\text { Pre- } \\
\text { immunized }\end{array}$ & log2FoldChange & P_value & q_value & Dysregulated & FC \\
\hline ENSG00000105205 & CLC & mRNA & 1.33294 & 35.9944 & -4.75509 & $\begin{array}{l}5.00 \mathrm{E}- \\
05\end{array}$ & 0.006587 & Down & 27.00379 \\
\hline ENSG00000239839 & DEFA3 & mRNA & 4.43212 & 68.8862 & -3.95815 & $\begin{array}{l}5.00 \mathrm{E}- \\
05\end{array}$ & 0.006587 & Down & 15.54254 \\
\hline ENSG00000204388 & HSPA1B & mRNA & 78.3372 & 5.27778 & 3.89169 & $\begin{array}{l}5.00 \mathrm{E}- \\
05\end{array}$ & 0.006587 & Up & 14.84279 \\
\hline ENSG00000164047 & CAMP & mRNA & 0.592677 & 7.0903 & -3.58053 & 0.00065 & 0.049892 & Down & 11.96319 \\
\hline ENSG00000125740 & FOSB & mRNA & 96.1971 & 11.1305 & 3.11147 & $\begin{array}{l}5.00 \mathrm{E}- \\
05\end{array}$ & 0.006587 & Up & 8.642628 \\
\hline ENSG00000162772 & ATF3 & mRNA & 23.1743 & 3.18224 & 2.86441 & $\begin{array}{l}5.00 \mathrm{E}- \\
05\end{array}$ & 0.006587 & Up & 7.28238 \\
\hline ENSG00000111537 & IFNG & mRNA & 11.2211 & 1.54555 & 2.86002 & 0.0002 & 0.020468 & Up & 7.260254 \\
\hline ENSG00000276085 & CCL3L3 & mRNA & 51.5995 & 7.47768 & 2.7867 & $\begin{array}{l}5.00 \mathrm{E}- \\
05\end{array}$ & 0.006587 & Up & 6.900496 \\
\hline ENSG00000090104 & RGS1 & mRNA & 52.4469 & 7.78688 & 2.75174 & $\begin{array}{l}5.00 \mathrm{E}- \\
05\end{array}$ & 0.006587 & Up & 6.73529 \\
\hline ENSG00000277632 & CCL3 & mRNA & 80.3514 & 12.1697 & 2.72303 & $\begin{array}{l}5.00 \mathrm{E}- \\
05\end{array}$ & 0.006587 & Up & 6.602581 \\
\hline ENSG00000141682 & PMAIP1 & mRNA & 49.184 & 8.15661 & 2.59215 & $\begin{array}{l}5.00 \mathrm{E}- \\
05\end{array}$ & 0.006587 & Up & 6.029967 \\
\hline ENSG00000125538 & IL1B & mRNA & 62.8604 & 10.7286 & 2.55069 & $\begin{array}{l}5.00 \mathrm{E}- \\
05\end{array}$ & 0.006587 & Up & 5.859144 \\
\hline ENSG00000118503 & TNFAIP3 & mRNA & 263.218 & 50.6895 & 2.3765 & $\begin{array}{l}5.00 \mathrm{E}- \\
05\end{array}$ & 0.006587 & Up & 5.192754 \\
\hline ENSG00000185022 & MAFF & mRNA & 32.1323 & 6.22367 & 2.36818 & $\begin{array}{l}5.00 \mathrm{E}- \\
05\end{array}$ & 0.006587 & Up & 5.162894 \\
\hline ENSG00000255398 & HCAR3 & mRNA & 14.3272 & 2.78187 & 2.36463 & $\begin{array}{l}5.00 \mathrm{E}- \\
05\end{array}$ & 0.006587 & Up & 5.150206 \\
\hline ENSG00000114315 & HES1 & mRNA & 2.92857 & 0.57765 & 2.34193 & 0.00015 & 0.016397 & Up & 5.069804 \\
\hline ENSG00000110848 & CD69 & mRNA & 219.951 & 43.9565 & 2.32303 & $\begin{array}{l}5.00 \mathrm{E}- \\
05\end{array}$ & 0.006587 & Up & 5.00382 \\
\hline ENSG00000169429 & CXCL8 & mRNA & 24.4288 & 4.93953 & 2.30614 & $\begin{array}{l}5.00 \mathrm{E}- \\
05\end{array}$ & 0.006587 & Up & 4.945581 \\
\hline ENSG00000143507 & DUSP10 & mRNA & 35.2674 & 7.27819 & 2.27668 & $\begin{array}{l}5.00 \mathrm{E}- \\
05\end{array}$ & 0.006587 & Up & 4.845616 \\
\hline ENSG00000112149 & CD83 & mRNA & 62.9776 & 13.0436 & 2.2715 & $\begin{array}{l}5.00 \mathrm{E}- \\
05\end{array}$ & 0.006587 & Up & 4.828249 \\
\hline
\end{tabular}

\section{Genomic Features Of Lncrnas And Mrnas}

To know more about the genomic features of the IncRNA and mRNA in volunteers, we systematically analyzed the feature of IncRNA in this study and compared them with protein-coding genes. The result show that the average expression level of IncRNA were lower than mRNAs (Fig. 5A). The exons number and the lengths of IncRNA was also less and shorter than that of mRNAs (Fig. 5B, C) Furthermore, most of the mRNAs had a longer ORFs than the IncRNA (Fig. 5D).

\section{Functional Prediction Of Rabv Vaccine Induced Co-localized Lncrnas}

To better understand the functions of differentially expressed co-localized IncRNA in RABV vaccine immunized volunteers, GO term and KEGG pathway analysis was performed. The GO analysis result reveal that the genes colocate with differentially expressed IncRNA were highly enriched in biological 
processes like extracellular vesicular exosome, extracellular organelle and extracellular membrane-bounded organelle process. The top $20 \mathrm{GO}$ terms are presented (Fig. 6A).

What's more, KEGG was also used to investigate the involved biological pathways of the differentially expressed IncRNA. The top20 significant enriched pathways terms exhibited in Fig. 6B. Some infectious disease pathways were shown, such Chagas disease (American trypanosomiasis), malaria, tuberculosis, herpes simplex infection, hepatitis $\mathrm{C}$ and measles (Fig. 6B). These finding suggested that IncRNA regulate the infectious process after RABV vaccine immunized.

\section{Validation Of Selected Differentially Expressed Lncrnas By Rt-qpcr}

To valiate the rabies vaccine induced IncRNA expression changes detected by RNA-seq, five downregulated expressed IncRNA (XLOC_005414, XLOC_062716, XLOC_005417, ENSG00000197182, XLOC_000161) and one upregulated expressed IncRNA (ENSG00000254162) were selected to validate by using RT-qPCR. The results were shown in Fig. 7. Both the results of RT-qPCR were similar to the RNA-seq result, which implicated the good reliability and reproducibility of the IncRNA changes determined by RNA-seq.

\section{Discussion}

Rabies is one of the most deadly infectious diseases and was fatal once the clinical symptoms developed, and it remains a threat to public health. Currently, without certain cure, rabies can be prevented by rabies immune globulin (RIG) or rabies vaccine injection once a bite or exposure to saliva from an infected animal. As a result, annually almost 59,000 global human deaths caused by rabies and estimated 15 million people receive post-exposure prophylaxis annually for exposures [39]. Pre-exposure prophylaxis (PEP) protect the high-risk group with the presence of rabies-specific virus-neutralizing antibodies (VNAs). Unfortunately, the pre-exposure prophylaxis or post-exposure prophylaxis was not only need multiple injections but also time-consuming and expensive [40]. Now, there is an urgent need to develop a new biologicals to potentially replace existed prophylaxis with cost-effective alternatives to the human rabies elimination.

During the infection, the viral induce the host innate immune system and secretion lots cytokines, chemokine like type I IFN [9, 10]. And the type I IFN active JAK/STAT signaling pathway result in the expression of ISGs, which had diverse antiviral functions [13-15]. A important feature of the RABV is that the RABV can replicate in the central nervous system (CNS) where was an immunologically privileged area of the host [41]. Therefore, when the RABV infected like bites or scratches, the RABV G protein binds to the nicotinic acetylcholine receptor and later enter the CNS. When the RABV exposed to the innate and adaptive immune responses, it induced some molecules and chemokines, like NF-KB, type I IFN-regulated responses and toll-like receptors (TLR) to against the elimination [42,43] [44]. Though lots efforts had done to investigate the RABV biology and anti-RABV immune response, the mechanism of how the RABV escape the elimination in the host immune response is still need deep-going.

In our previous work, we found that the RABV infection can significantly change the protein-coding profile of host cell in vitro by RNA-sequencing, and identified some genes that function against viral replication, such as ISG15 and UBA7 [45, 46]. What's more, we also investigated the host immune response during the RABV infection in a mouse model and found something interesting (unpublished data), but how the human host immune response during the infection is still nuclear. Raising data had suggested that IncRNA involve in modulated many biological process like gene epigenetic modulation, protein scaffolding, cell development and more [47]. LncRNAs also have been implicated in the pathogenesis and response to bacterial and viral infections. Reports had reveal that HIV[27], SARS-CoV[48] and some viral can induce IncRNA differentially expressed. On the other way out, the viral-induced IFN pathway can regulate the expression of several IncRNA [49]. Accumulating evidences supported that many viral infections induced specific IncRNA which in turn play an antiviral role in host immune responses $[21,50]$. Though cellular IncRNA were reported in many virus infections, i.e. enterovirus, influenza, hepatitis $B$ and $C$ viruses, the role of IncRNA in the RABV infection remains unclear.

Here we analysis the expression profile of IncRNA and mRNA in PBMC after RABV vaccine immunized. A total of 33 InRNA and 427 mRNA were differentially expressed in RABV vaccine immunized volunteers. In the IncRNA, only one annotated IncRNA ENSG00000254162 was upregulated with a FC of 4.38 and the other 32 IncRNA were downregulated with a FC range from 1.75 to 7.07 (Fig. 3). To be noted, five of the top 6 downregulated IncRNA were novel ones (Table 1). With the Ensembl genome browser and NCBI data base, lookuped all the differentially expressed IncRNA, we found that it involved the chromatin regulatory like ENSG00000269821 and hormonal regulatory like ENSG00000266962. However, the only one upregulated IncRNA ENSG00000254162 was short of research and whether the novel IncRNA were relevant with RABV vaccine immunization is still need to be investigate. In the 427 differential expressed mRNAs, 321 of them were upregulated and 106 were downregulated. The top 10 differential expression mRNA contained 3 down regulated mRNA and seven upregulated mRNA with a FC range from 6.60 to 27.00 (Table 2). Like DEAF3 (GENE ID: ENSG00000239839, defensin alpha 3) and CAMP (GENE ID: ENSG00000164047, cathelicidin antimicrobial peptide) are both belong to the antimicrobial peptide. They are the first line of defense against a wide range of pathogens. Data had proved that defensin can inhibit some viral infection, like HIV, influenza A virus (IAV) and so on [51-53]. Also, data showed that the mRNA expression of INF- $y$ and activating transcription factor 3 (ATF3) were higher than pre-immunized. What's more, ATF3 can modulate the IFN - $\gamma$ expression to regulate viral infection in mice [54] [55]. It demonstrated that RABV vaccine can induce host immune against the viral infection.

Base on the unique structure and characteristic unlike protein coding genes and microRNAs, IncRNA sequences are currently uninformative for predicting function[56]. The regulation effects of IncRNA are mainly by regulating the expression of the neighboring protein coding genes [57]. Here GO term and KEGG pathway analysis was performed to investigate the functions of differentially expressed IncRNA in RABV vaccine immunized volunteers. GO terms were significantly enriched in biological processes like extracellular vesicular exosome, extracellular organelle and extracellular membrane-bounded organelle process. The involved biological pathways of the differentially expressed IncRNA analysis by KEGG contained many infectious diseases like Chagas disease (American trypanosomiasis), malaria, tuberculosis, herpes simplex infection, hepatitis $\mathrm{C}$ and measles. What's more, the viral induced immune responses

Page $7 / 15$ 
pathway like the toll-like receptor signaling pathway and TGF-beta signaling pathway were significant enriched pathways. Taking together, it suggested that IncRNA take part in host immune response during the RABV vaccine immunized through various pathways.

\section{Conclusions}

In a brief, it is first to reveal the IncRAN expression profile and function of differentially expressed IncRNA in RABV vaccine immunized model which mimic the RABV infection in human. In the present study, some IncRNA are identified and the data suggested IncRNA play an important role in regulating gene expression after RABV vaccine immunized and exert important biological effects. It may be very valuable for the development of new effective therapeutic drugs for rabies or provide novel strategies for vaccine designation.

\section{Abbreviations}

RABV

rabies virus; IncRNA:Iong noncoding RNA; GO:gene oncology; KEGG:Kyoto Encyclopedia of Genes and Genomes; JAK/STAT:Janus-activated kinase/signal transducer; ISGs:IFN-stimulated genes; PBMCs:peripheral blood mononuclear cells; RT-qPCR:quantitative real-time polymerase chain reaction; FC:fold change; RIG:rabies immune globulin; PEP:Pre-exposure prophylaxis; VNAs:virus-neutralizing antibodies; TLR:toll-like receptors; CNS:central nervous system.

\section{Declarations}

\section{Authors' contributions}

The study was designed by PZ. PZ, KH and PZ drafted the manuscript. WJ, ZP, and GH contributed to the field research. PZ and KH completed the experiment. $\mathrm{PZ}, \mathrm{KH}, \mathrm{PZ}$, SY and XX collected and analyzed the data. All authors assisted in reviewing and editing the manuscript. All authors read and approved the final manuscript.

\section{Funding}

This study was supported by The National Key Research and Development Program of China (Grant No.: 2016YFD0500405 to Dr. Pingsen Zhao), The National Key Research and Development Program of China (Grant No.: 2017 YFD 0501705 to Dr. Pingsen Zhao) and Natural Science Foundation of Guangdong Province, China (Grant No.: 2016A030307031 to Dr. Pingsen Zhao).

\section{Availability of data and materials}

All data analyzed during the study are included in this published article (and its supplementary information files) and are available from the included studies, which are fully referenced.

\section{Ethical conduct of research}

The authors state that they have obtained appropriate institutional review board approval or have followed the principles outlined in the Declaration of Helsinki for all animal experimental investigations. All animal experiments were performed following the National Institute of Health Guide for the Care and Use of Laboratory Animals, and the experimental protocols were approved by the Research Ethics Committee of Yuebei People's Hospital, Shantou University Medical College, Shaoguan, China.

\section{Consent for publication}

Not applicable.

\section{Competing interests}

The authors declare that they have no competing interests.

\section{Author details}

${ }^{1}$ Department of Laboratory Medicine, Yuebei People's Hospital, Shantou University Medical College, Shaoguan, China

${ }^{2}$ Shaoguan Municipal Quality Control Center for Laboratory Medicine, Shaoguan, China

${ }^{3}$ Department of Endocrine and Metabolic Diseases, Longhu Hospital, The First Affiliated Hospital of Shantou University Medical College, Shantou, China

${ }^{4}$ West China School of Public Health and West China Fourth Hospital, Sichuan University, Chengdu, China

${ }^{5}$ Institute of Military Veterinary, Academy of Military Medical Sciences, Changchun, China

\section{References}

1. Davis BM, Rall GF, Schnell MJ. Everything You Always Wanted to Know About Rabies Virus (But Were Afraid to Ask). Annu Rev Virol. 2015;2(1):451-71. 
2. Rupprecht CE, Hanlon CA, Hemachudha T. Rabies re-examined. Lancet Infect Dis. 2002;2(6):327-43.

3. Dato VM, Campagnolo ER, Long J, et al. A Systematic Review of Human Bat Rabies Virus Variant Cases: Evaluating Unprotected Physical Contact with Claws and Teeth in Support of Accurate Risk Assessments. PLoS One. 2016;11(7):e0159443.

4. Knobel DL, Cleaveland S, Coleman PG, et al. Re-evaluating the burden of rabies in Africa and Asia. Bulletin of the World Health Organization. 2005;83(5):360.

5. Rupprecht CE, Hanlon CA, Hemachudha T. Rabies re-examined. Lancet Infectious Diseases. 2002;2(6):327-43.

6. Wunner WH, Larson JK, Dietzschold B, et al., The molecular biology of rabies viruses, Rev Infect Dis. 10 Suppl 4 (1988) S771-784.

7. Coulon P, Derbin C, Kucera P, et al. Invasion of the peripheral nervous systems of adult mice by the CVS strain of rabies virus and its avirulent derivative Av01. J Virol. 1989;63(8):3550-4.

8. Lafon M. Evasive strategies in rabies virus infection. Adv Virus Res. 2011;79:33-53.

9. Iwasaki A. A Virological View of Innate Immune Recognition. Annual Review of Microbiology. 2012;66(66):177.

10. Goubau D, Deddouche S, Reis, eSC. Cytosolic sensing of viruses. Immunity. 2013;38(5):855-69.

11. Ivashkiv LB, Donlin LT. Regulation of type I interferon responses. Nat Rev Immunol. 2014;14(1):36-49.

12. Faul EJ, Wanjalla CN, Suthar MS, et al. Rabies virus infection induces type I interferon production in an IPS-1 dependent manner while dendritic cell activation relies on IFNAR signaling. Plos Pathogens. 2013;6(7):e1001016.

13. Levy DE Jr. DJ, STATS: Transcriptional control and biological impact. Nature Reviews Molecular Cell Biology. 2002;3(9):651-62.

14. Macmicking JD. Interferon-inducible effector mechanisms in cell-autonomous immunity. Nat Rev Immunol. 2012;12(5):367-82.

15. Schoggins JW, Wilson SJ, Panis M, et al. A diverse range of gene products are effectors of the type I interferon antiviral response. Nature. 2011;472(7344):481-5.

16. Schoggins JW, Wilson SJ, Panis M, et al. A diverse range of gene products are effectors of the type I interferon antiviral response. Nature. 2011;472(7344):481-5.

17. Schoggins JW, MacDuff DA, Imanaka N, et al. Pan-viral specificity of IFN-induced genes reveals new roles for cGAS in innate immunity. Nature. 2014;505(7485):691-5.

18. Zhao P, Jiang T, Zhao L, et al. Inhibition of rabies virus replication by interferon-stimulated gene 15 and its activating enzyme UBA7. Infection Genetics Evolution. 2017;56:44.

19. Chopy D, Detje CN, Lafage M, et al. The type I interferon response bridles rabies virus infection and reduces pathogenicity. J Neurovirol. 2011;17(4):35367.

20. Li X, Wu Z, Fu X, et al. Long Noncoding RNAs: Insights from Biological Features and Functions to Diseases. Med Res Rev. 2013;33(3):517-53.

21. Zhang Q, Jeang KT. Long noncoding RNAs and viral infections. Biomedicine. 2013;3(1):34-42.

22. Wang P, Xue Y, Han Y, et al. The STAT3-binding long noncoding RNA Inc-DC controls human dendritic cell differentiation. Science. 2014;344(6181):310-3.

23. Huarte M, Guttman M, Feldser D, et al. A large intergenic noncoding RNA induced by p53 mediates global gene repression in the p53 response. Cell. 2010;142(3):409-19.

24. Sauvageau M, Goff LA, Lodato S, et al. Multiple knockout mouse models reveal lincRNAs are required for life and brain development. Elife. 2013;2:e01749.

25. Heward JA, Lindsay MA. Long non-coding RNAs in the regulation of the immune response. Trends Immunol. 2014;35(9):408-19.

26. Winterling C, Koch M, Koeppel M, et al. Evidence for a crucial role of a host non-coding RNA in influenza A virus replication. RNA Biol. 2014;11(1):66-75.

27. Zhang Q, Chen $\mathrm{CY}$, Yedavalli VS, et al., NEAT1 long noncoding RNA and paraspeckle bodies modulate HIV-1 posttranscriptional expression, MBio. 4 (1) (2013) e00596-00512.

28. Du Y, Kong G, You X, et al. Elevation of highly up-regulated in liver cancer (HULC) by hepatitis $B$ virus $\mathrm{X}$ protein promotes hepatoma cell proliferation via down-regulating p18. J Biol Chem. 2012;287(31):26302-11.

29. Fortes P, Morris K. Long noncoding RNAs in viral infections. Virus Res. 2016;212:1-11.

30. Krishnamurthy M, Beihua D, Michael G, et al. Small self-RNA generated by RNase L amplifies antiviral innate immunity. Nature. 2007;448(7155):816.

31. Barriocanal M, Carnero E, Segura V, et al. Long Non-Coding RNA BST2/BISPR is Induced by IFN and Regulates the Expression of the Antiviral Factor Tetherin. Frontiers in Immunology. 2014;5:655

32. Ouyang J, Zhu X, Chen Y, et al, NRAV, a Long Noncoding RNA, Modulates Antiviral Responses through Suppression of Interferon-Stimulated Gene Transcription, Cell Host \& Microbe. 16 (5) (2014) 616-626.

33. Nishitsuji H, Ujino S, Yoshio S, et al. Long noncoding RNA \#32 contributes to antiviral responses by controlling interferon-stimulated gene expression. Proceedings of the National Academy of Sciences of the United States of America. 2016;113(37):10388-93.

34. Zhao P, Liu S, Zhong Z, et al. Analysis of expression profiles of long noncoding RNAs and mRNAs in brains of mice infected by rabies virus by RNA sequencing. Sci Rep. 2018;8(1):11858-

35. Trapnell C, Williams BA, Pertea G, et al. Transcript assembly and quantification by RNA-Seq reveals unannotated transcripts and isoform switching during cell differentiation. Nat Biotechnol. 2010;28(5):511-5.

36. Liang S, Haitao L, Dechao B, et al. Utilizing sequence intrinsic composition to classify protein-coding and long non-coding transcripts. Nucleic Acids Res. 2013;41(17):e166-6. 
37. Lei K, Yong Z, Zhi-Qiang Y, et al. CPC: assess the protein-coding potential of transcripts using sequence features and support vector machine. Nucleic Acids Res. 2007;35:W345. (Web Server issue).

38. Park HJ, Wang L, Wang S, et al. CPAT: Coding-Potential Assessment Tool using an alignment-free logistic regression model. Nucleic Acids Res. 2013;41(6):e74-4.

39. Fisher CR, Streicker DG, Schnell MJ. The spread and evolution of rabies virus: conquering new frontiers. Nat Rev Microbiol. 2018;16(4):241.

40. Rupprecht C, Kuzmin I, Meslin F. Lyssaviruses and rabies: current conundrums, concerns, contradictions and controversies, F1000research. 6 (184) (2017) 184.

41. Lewis P, Fu Y, Lentz TL. Rabies virus entry at the neuromuscular junction in nerve-muscle cocultures. Muscle Nerve. 2015;23(5):720-30.

42. Faul EJ, Wanjalla CN, Suthar MS, et al. Rabies virus infection induces type I interferon production in an IPS-1 dependent manner while dendritic cell activation relies on IFNAR signaling. PLoS Pathog. 2010;6(7):e1001016.

43. Li J, Faber M, Dietzschold B, et al. The role of toll-like receptors in the induction of immune responses during rabies virus infection. Adv Virus Res. 2011;79:115-26.

44. Prehaud C, Megret F, Lafage M, et al. Virus infection switches TLR-3-positive human neurons to become strong producers of beta interferon. J Virol. 2005;79(20):12893-904.

45. Zhao P, Yang Y, Feng H, et al. Global gene expression changes in BV2 microglial cell line during rabies virus infection. Infect Genet Evol. $2013 ; 20: 257-69$.

46. Zhao P, Jiang T, Zhong Z, et al. Inhibition of rabies virus replication by interferon-stimulated gene 15 and its activating enzyme UBA7. Infect Genet Evol. 2017;56:44-53.

47. Yu AD, Wang Z, Morris KV. Long noncoding RNAs: a potent source of regulation in immunity and disease. Immunology Cell Biology. $2015 ; 93(3): 277$.

48. Peng $X$, Gralinski L, Armour CD, et al., Unique signatures of long noncoding RNA expression in response to virus infection and altered innate immune signaling, MBio. 1 (5) (2010).

49. Carnero E, Barriocanal M, Segura V, et al. Type I Interferon Regulates the Expression of Long Non-Coding RNAs. Frontiers in Immunology. $2014 ; 5: 548$.

50. Ouyang J, Hu J, Chen JL. IncRNAs regulate the innate immune response to viral infection. Wiley Interdisciplinary Reviews Rna. 2016;7(1):129-43.

51. Chang TL, Vargas J, Delportillo A, et al. Dual role of alpha-defensin-1 in anti-HIV-1 innate immunity. Journal of Clinical Investigation. 2005;115(3):76573.

52. Salvatore M, Garcia-Sastre A, Ruchala P, et al. alpha-Defensin inhibits influenza virus replication by cell-mediated mechanism(s). Journal of Infectious Diseases. 2007;196(6):835-43.

53. Demirkhanyan LH, Marin M, Padillaparra S, et al. Multifaceted Mechanisms of HIV-1 Entry Inhibition by Human a-Defensin. Journal of Biological Chemistry. 2012;287(34):28821-38.

54. Rosenberger CM, Clark AE, Treuting PM, et al., ATF3 Regulates MCMV Infection in Mice by Modulating IFN-y Expression in Natural Killer Cells, Proceedings of the National Academy of Sciences of the United States of America. 105 (7) (2008) 2544-2549.

55. Biron CA, Brossay L. NK cells and NKT cells in innate defense against viral infections. Current Opinion in Immunology. 2001;13(4):458-64.

56. Mercer TR, Dinger ME, Mattick JS. Long non-coding RNAs: insights into functions. Nat Rev Genet. 2009;10(3):155-9.

57. Wilusz JE, Sunwoo H, Spector DL. Long noncoding RNAs: functional surprises from the RNA world. Genes Dev. 2009;23(13):1494-504.

\section{Figures}

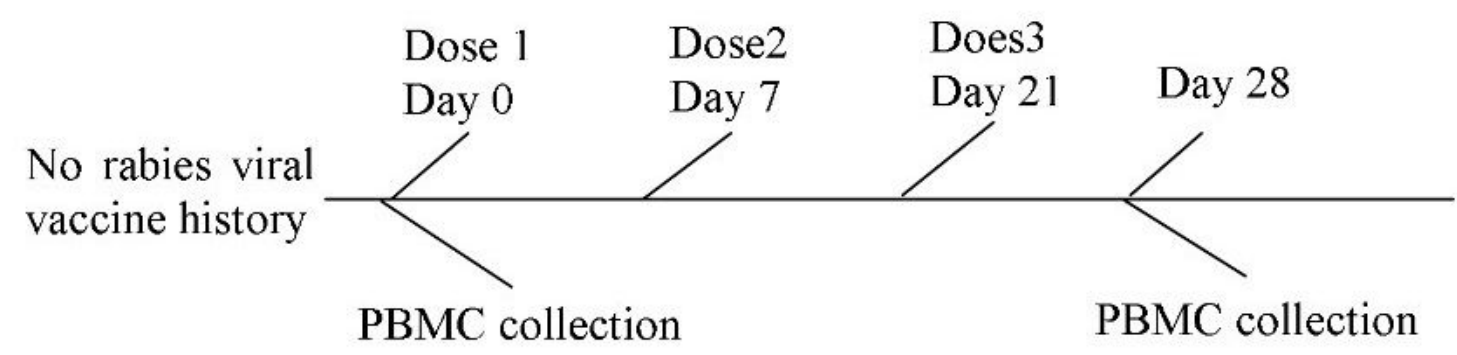

\section{Figure 1}

The immunization procedure of rabies vaccine. The immunized procedure contained 3 injections: 1 dose was injected on 0 days, 7 days, 21 days. And $10 \mathrm{ml}$ peripheral blood samples were obtained at day 0 before vaccinated and the 28-days, the PBMCs had been separated immediately for further sequence. 
A

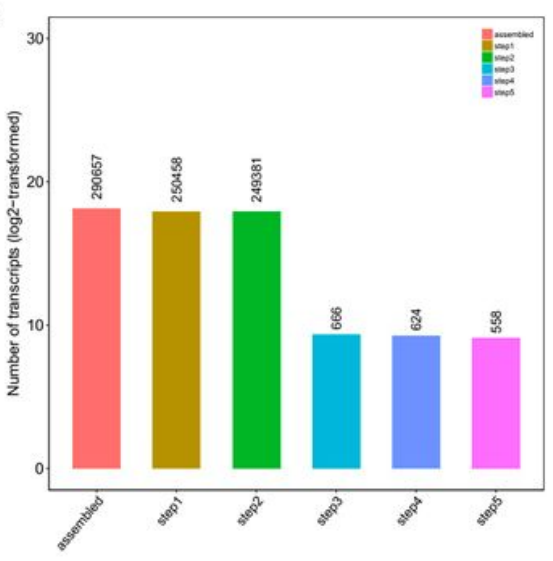

B

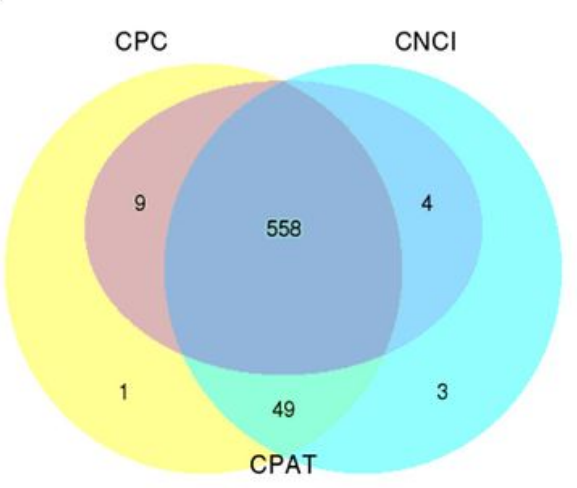

C

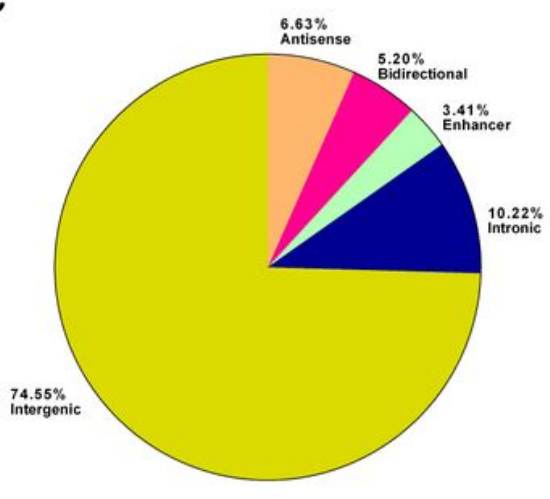

Figure 2

Identification of novel IncRNA in PBMCs after RABV vaccine immunization. (A) Screen of IncRNA in RABV vaccine immunized volunteers. (B) Evaluating the coding capacity of assembled transcripts using CNCl, CPC and CPAT. (C) Classification of IncRNA based on genomic location.
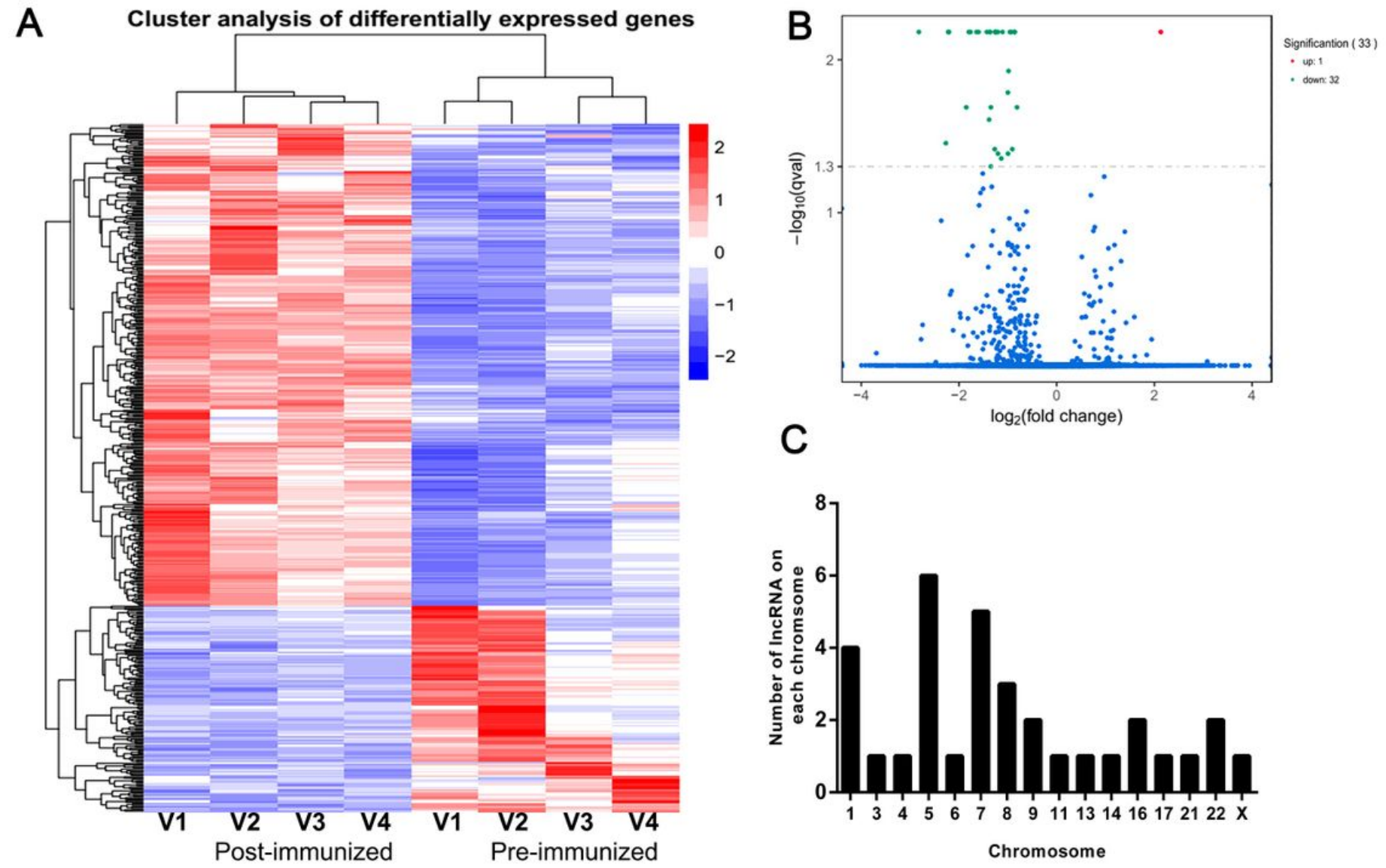

Figure 3

The expression profiles of IncRNAs in PBMCs of four volunteers pre- and post-immunization. (A) Hierarchical clustering of differentially expressed IncRNA. (B) Volcano plot of differentially expressed IncRNA in PBMC post-immunized compared with pre-immunized. (C) Distribution of differentially expressed IncRNA in each chromosome. 
A

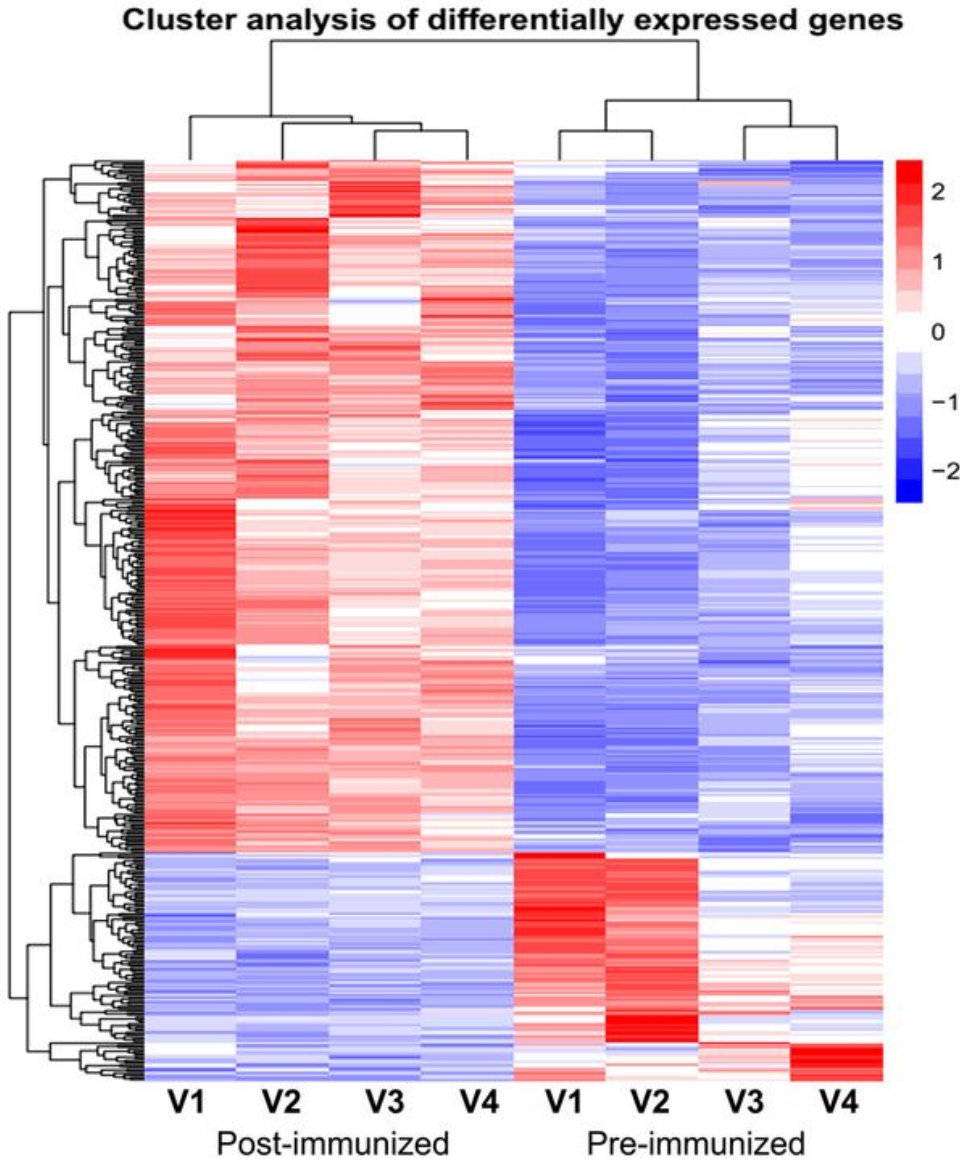

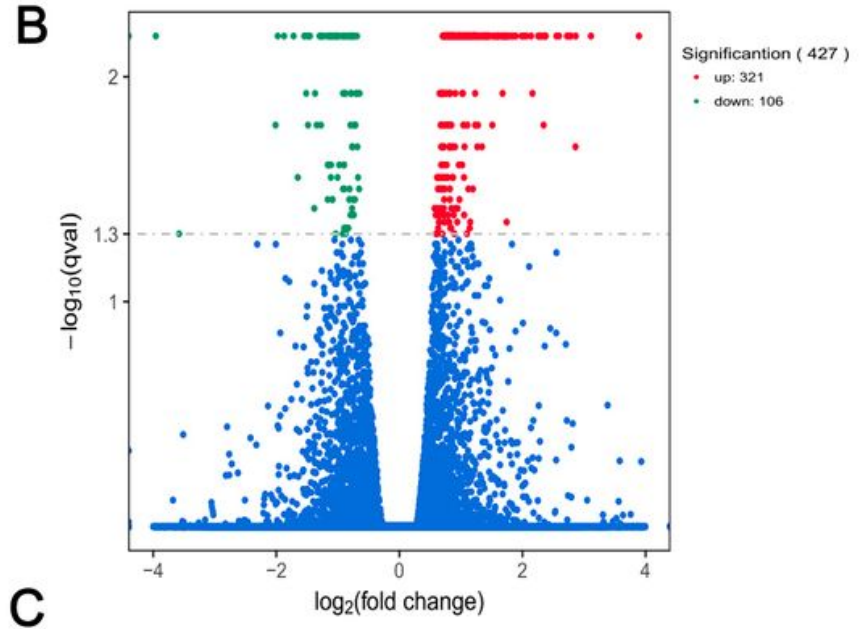

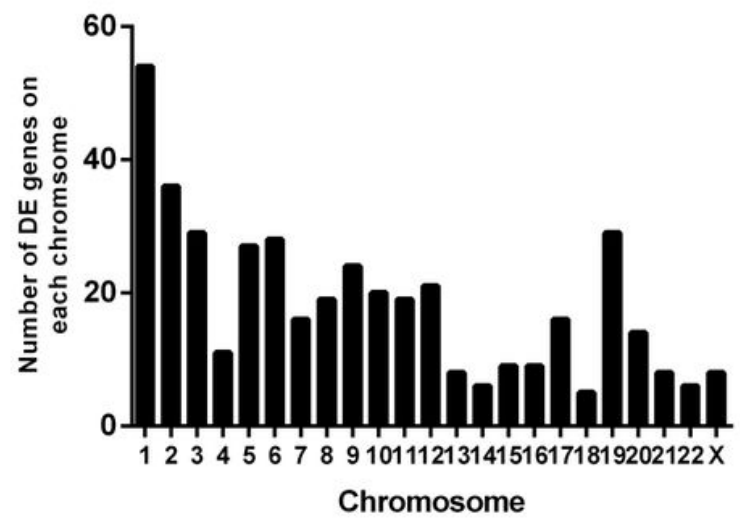

Figure 4

The expression profiles of mRNAs in PBMCs in four volunteers. (A) Hierarchical clustering of differentially expressed mRNAs. (B) Volcano plot of differentially expressed mRNAs in RABV vaccine immunized volunteers PBMC compared with pre-immunized. (C) Distribution of differentially expressed IncRNA in each chromosome. 
A
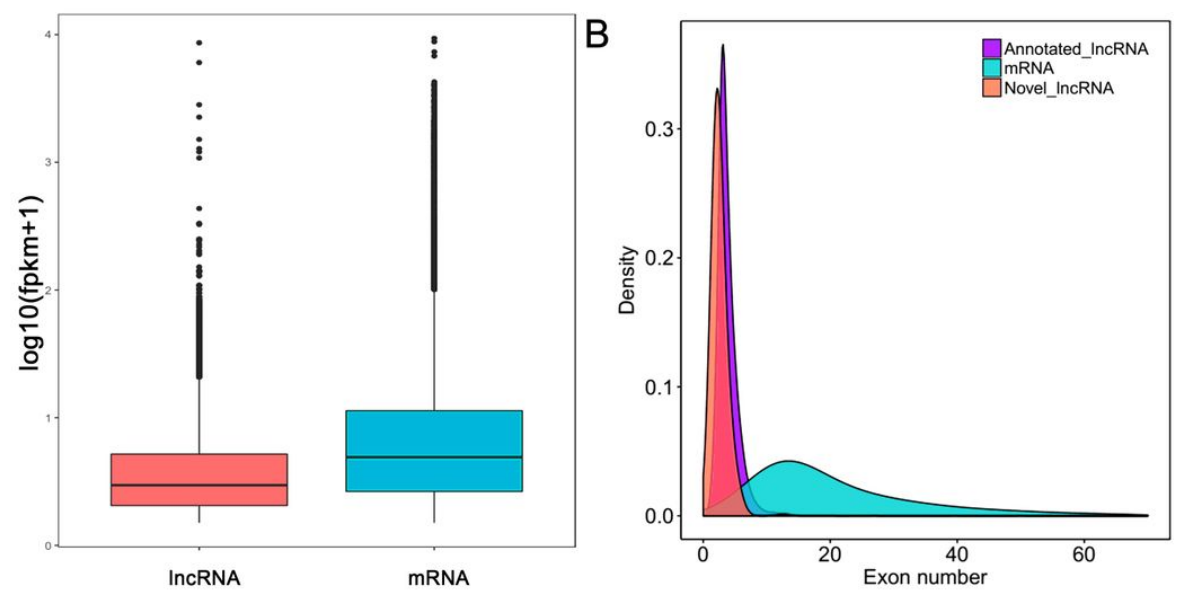

C

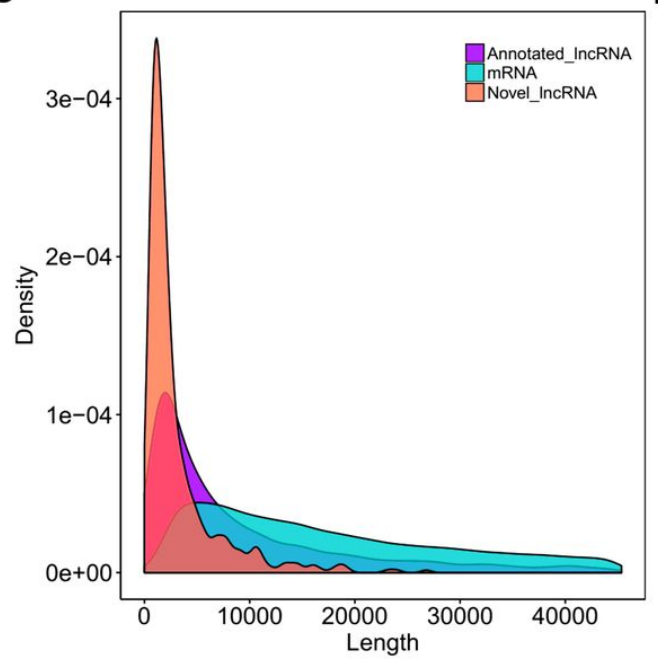

D

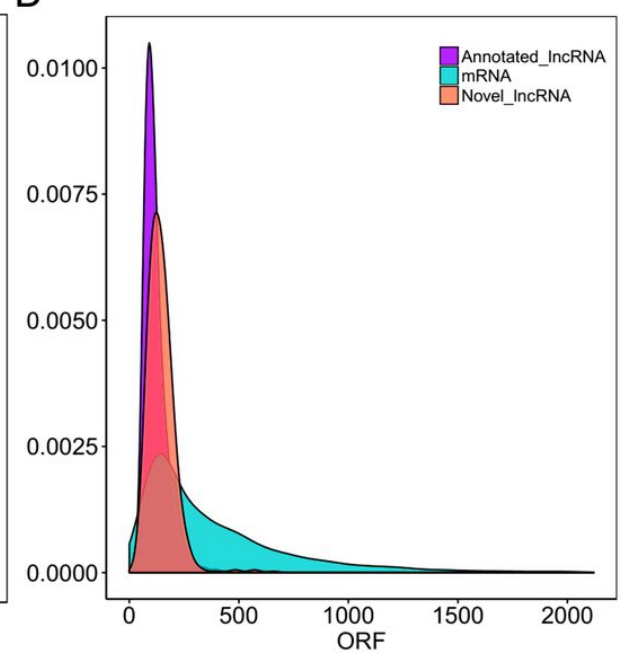

Figure 5

Genomic features of IncRNAs and mRNAs. (A)Comparison of IncRNA and mRNAs expression level. (B) Comparison of exon number between IncRNA and mRNAs (C) Length distribution of IncRNA and mRNAs. (D) Length of ORFs between IncRNA and mRNAs. 


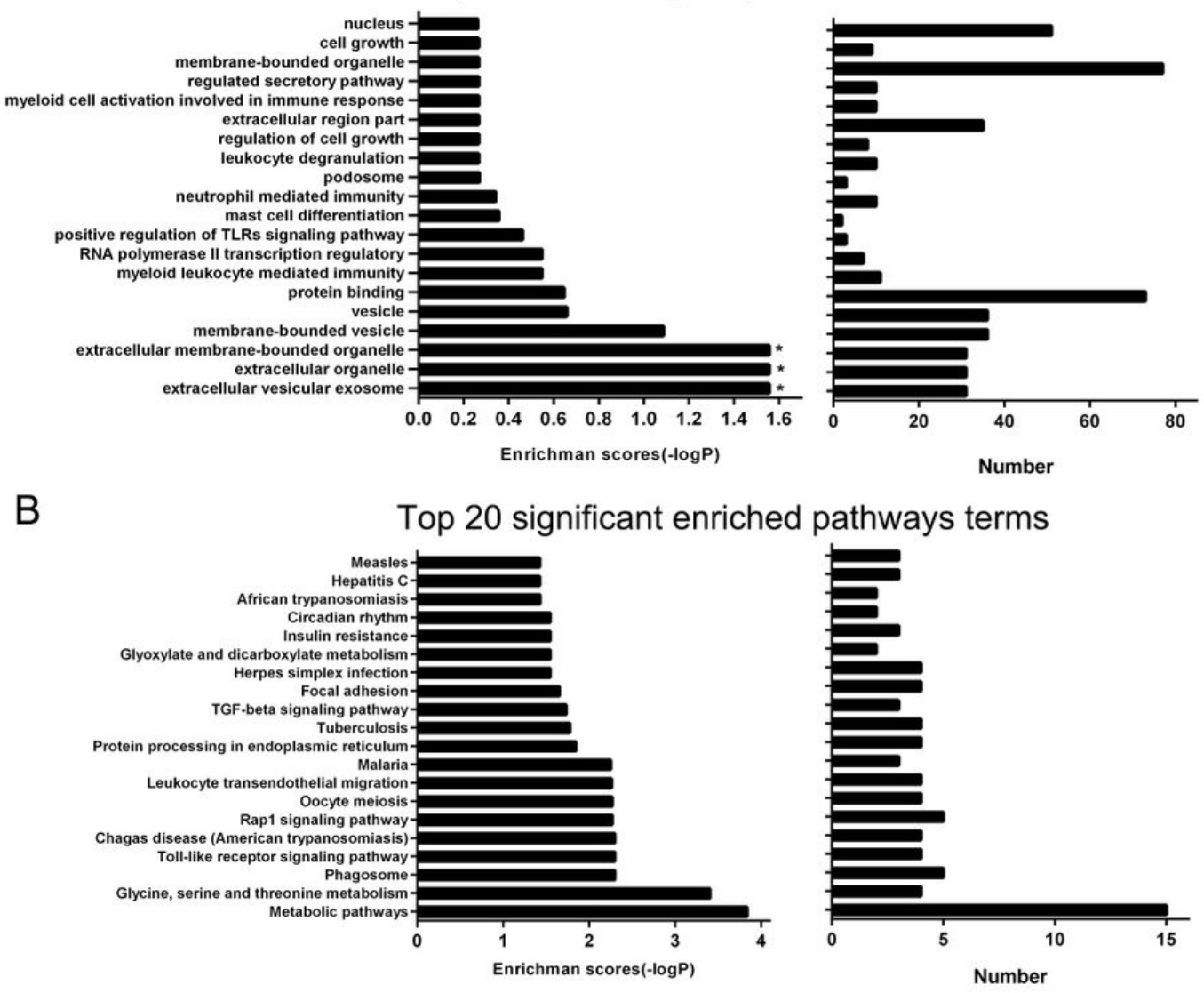

Figure 6

Go enrichment and KEGG pathway analysis of target genes of differentially expressed IncRNAs. (A) Top 20 GO biological processes enriched among target genes of differentially expressed IncRNA. (B) The top 20 pathways enriched among target genes of differentially expressed IncRNA. Right: the enrichment scores $(-\log P)$, left: the number of each. 


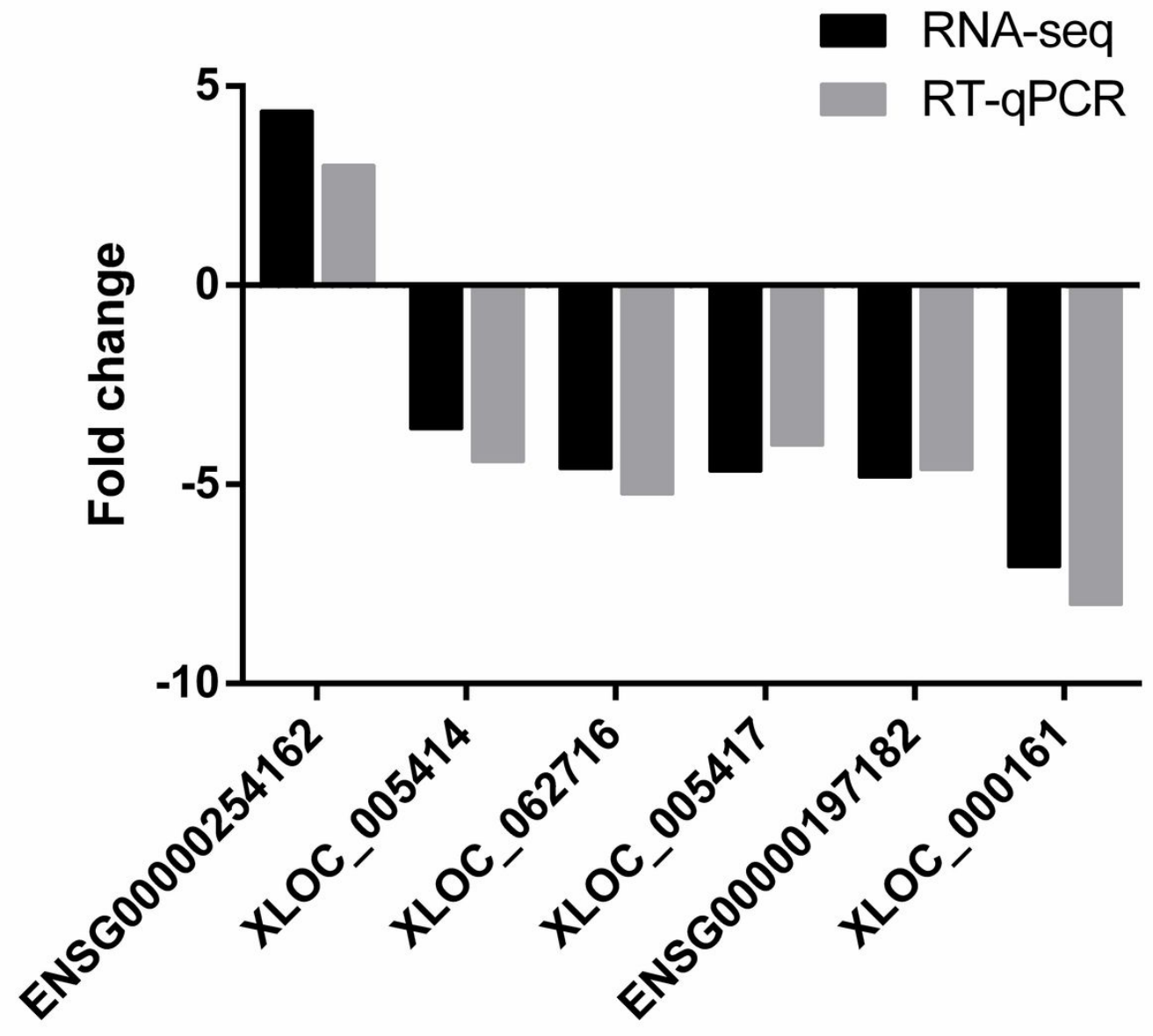

Figure 7

Validation of selected differentially expressed IncRNAs by RT-qPCR Base on the data of RAN-seq, five downregulated expressed IncRNA (XLOC_005414, XLOC_062716, XLOC_005417, ENSG00000197182, XLOC_000161) and one upregulated expressed IncRNA (ENSG00000254162) were selected to validate by using RT-qPCR. 